\title{
Professional Institutional Engagement as a Framework for Negotiating Space for Teacher Autonomy in Authoritarian Work Environments
}

\author{
Wabule Alice ${ }^{1}$ \\ CUganda Martyrs University
}

\begin{abstract}
Teacher involvement in decision making at school leads to increased motivation, engagement and empowerment. Using the Participatory Action Research (PAR) framework to increase opportunities for teacher participation in school affairs, we found that traditional hierarchical power relations and bureaucracy are barriers to teachers' autonomy, participation and engagement in the day-to-day decision making process. The conceptual model of Professional Institutional Engagement (PIE) was used to enable teachers to frame the challenges to autonomy and decision making within their professional practice, craft interventional strategies to mitigate them, which included open communication, reflection and dialogue within the school environment. The results highlighted that PIE provided a practical mechanism through which traditional hierarchical relations and bureaucracies were circumvented, resulting in increased collaboration, improved institutional communication; which motivated and engaged teachers.
\end{abstract}

Key words: Autonomy, Participatory Action research, Professional Institutional Engagement, Professionalism, Uganda

Engagement Institutionnel Professionnel (EIP) comme Cadre de Négociation de l'Espace pour l'Autonomie d'Enseignants dans des Milieux de Travail Très Autoritaires

\section{Résumé}

L'engagement des enseignants dans le processus de prise de décision à l'école conduit à une augmentation de motivation, engagement et affranchissement. Faisant usage du cadre de Recherche d'Action Participative (RAP) dans le but d'augmenter les opportunités pour la participation des enseignants dans la gestion de l'école, nous avons trouvé que les hiérarchies traditionnelles de relations de pouvoir ainsi que la bureaucratie sont des barrières à l'autonomie, participation et engagement des enseignants dans le processus quotidien de prise de décision. Le modèle conceptuel d'Engagement Institutionnel Professionnel (EIP) fut utilisé pour permettre aux enseignants de formuler les défis à l'autonomie et processus de prise de décision dans leur pratique professionnel, d'élaborer des stratégies interventionnelles pour les mitiger, incluant la communication ouverte, réflexion et dialogue dans le milieu scolaire. Les résultats ont montré que EIP a fourni un mécanisme pratique à travers duquel les relations hiérarchiques traditionnelles ainsi que bureaucraties étaient dépassées, résultant ainsi en une grande collaboration et une communication institutionnelle améliorée, chose qui avait motivé et engagé les enseignants.

\footnotetext{
${ }^{1}$ Cavendish University, Kampala, Uganda; awabule@ cavendish.ac.ug
} 
Mots clés : Autonomie, Recherche d'Action Participative, Engagement Institutionnel Professionnel, Professionnalisme, Uganda

\section{Introduction}

Teacher autonomy is vital for quality teaching and professionalism. It is important for intrinsic motivation, self- determination and efficacy (Van veen 2008; Sahlberg 2011) and enhancing individual competence and skills development (Moses, 2007). With multiple definitional strands, this article adopts Friedson's (1994, p. 210) definition of autonomy as "the authority, expertise or skill that a professional needs in their practice". Critical to the teaching and learning process, autonomy gives teachers some degree of freedom to make meaningful contribution to decisions about their work and employment conditions (Van Veen 2008; Sahlberg 2011). Teachers feel autonomous when they have control over their work, have the freedom to handle matters using their own approaches, and participate freely in school affairs without feeling threatened by school authorities (Moses 2007).

Autonomy is also essential when establishing educational objectives such as assessing students' progress, deciding the curriculum and academic standards, engaging in continuous research and innovation, making administrative decisions and for providing organisational governance. Sahlberg (2011) posits that autonomy inspires teachers to strive for leadership. Accordingly, when teachers are involved in decision making, they willingly take-up responsibilities and engage in administrative and management tasks and as such a lack of autonomy leads to dissatisfaction, failed innovations, diminished self-evaluation, volatility in making meaningful contributions and teacher turnover (Van Veen 2008; Sahlberg 2011).

In framing this article, I have chosen to address three issues. The first, is professional autonomy and the dilemmas teachers face in the system of authoritarian power in a school environment. The second, provides the methodology and a brief illustration of the action research process that was employed in undertaking this research and the third introduces the concept of Professional Institutional Engagement (PIE) and how it could be applied to increasing teacher efficacy and autonomy. I conclude by suggesting PIE as a strategy for empowering teachers to dialogue on issues of concern in specific school contexts.

\section{Teacher Autonomy and Emerging Dilemmas: A Review of Literature}

Teachers like other professionals share the need for autonomy, prestige, status, safety, and respect (Pollard et al 2014). However, contemporary education and the teaching profession are faced with a diversity of challenges and dilemmas in regard to the extent to which they can manage their various responsibilities or make a contribution to external policy issues that have a direct impact on their professional practice. In most Sub-Saharan Africa's economies, teachers are faced with constant changes in education management policies that has not only created additional work for teachers (UNESCO 2014; Nengwekhulu 2010; Botha 2011), but also altered their relationships with the school administrators. Authoritarian and bureaucratic administrative systems are not only limited to Sub-Saharan Africa's economies, but extend to other countries elsewhere (Fullan 2010; Sahlberg 2011). The long-held assumption is that teachers should be closely monitored for their productivity (Van veen 2008; Sahlberg 2011; Fullan, 2010) which causes frustration, undue stress and impacts negatively on their self-esteem and performance.

In Uganda, education policies and management continue to be shaped largely by historical factors (Lugumba and Ssekamwa 1973), including expected professional etiquette which demands that the teachers follow specific rules. Any attempt by the teachers to voice their concerns is often interpreted as insubordination (Munakukaama 1997). The system of keeping teachers in subordinate positions of rule following provides little opportunity for professional autonomy and limits their agency and voice. Scholars in the field of professionalism and integrity such as Kunneman (2005), Banks (2009) and 
Sahlberg (2011), have criticised adherence to external rules saying that it prevents teachers from making independent judgements. While rules in the form of codes are necessary for guiding and safeguarding the professional status of practitioners (Banks 2009), they fall short of stimulating other aspects of professional practice such as motivations, qualities of character and moral perceptions.

Autonomy is vital for professionals to reflect systematically on issues in their practice and make choices that enhance the quality of their work (Sahlberg 2011). On the contrary, majority of the Ugandan teachers reported the difficulties encountered in harmonising what they believed was the right thing to do and what they actually did due to the coercive work environment (Wabule 2017). For instance, the teachers disclosed that they were frustrated by an academically oriented curriculum which conditioned them to coaching and teaching for testing in order to keep their jobs. In their view, the prevailing forces compelled them on what, when and how to teach.

Accepting to do wrong which is mostly intended to counter the insecurity and demoralisation that teachers encountered when children did not perform well at national exams is counterproductive to flexible thinking about practice (Pollard et al, 2014). In any case, the teachers need the authority to assess learners in a way that is fair and just to the student's diverse achievements. A practice where a teacher is tasked to openly account for the poor academic grades of learners is humiliating, demoralising and shows disrespect for the teacher's role and expertise in assessing learning outcomes (Fullan 2010; Sahlberg 2011; Pollard et al 2014). Summoning teachers leads to fear, tension, undue stress and stifles initiative to make meaningful contributions to school issues.

The teacher's inability to question school management creates challenging power relationships and hierarchical bureaucracies. Consequently, most decisions are made during staff meetings and the administrators assume to have reached consensus and yet, the teachers declared that they simply complied for fear of repercussions. In Uganda, teachers rarely participate in the policymaking process, they are strictly monitored, which in their view is not for purposes of providing technical support, but to ensure that certain government ideologies were promoted (Aguti and Fraser 2005). They also blamed the increasing lack of coherence in teaching on the ever-changing curriculum, which they had to implement without question.

Pointing to what they believe to be meaningful struggles for industrial action, teachers alleged that their voices were silenced by coercion and intimidation whenever a demand for autonomy was made. An oppressive system of school administration leads to less job satisfaction and low morale in teachers' work. Scholars who have worked closely with teachers contend that lack of autonomy kills the teacher's eagerness, aptitude, independence and self- control to take decisions and implement them (Sahlberg 2011; Fullan 2010; Van Veen 2008; Nengwekhulu 2008). Accordingly, autonomy is crucial for enhancing confidence, creativity, high level dedication and readiness to carry out decisions among the teaching staff. A lack of autonomy stifles peer support, collegial collaboration, teamwork, open communication and free interaction, which are necessary for effective teaching and learning.

This research established that an authoritarian school management system creates apathy among the teachers who resort to adopting coping strategies to survive, including passiveness (Freidson (1994). Thus, if the teachers are only required to play a role of providing whatever is demanded by their consumers, they ultimately lack commitment to both the pupils and the public (Friedson 1994, p. 215). Hence, strengthened interpersonal teacher relationships cultivate mutual cooperation and build fruitful engagement. Developing a new culture of effective participation in school tasks is paramount for illuminating the rigid systems of administration and structures that create fear and distrust.

\section{Methodology}


This was a qualitative study undertaken between 2012 and 2015 within the framework of Participatory Action Research (PAR), with the aim of improving some aspects of the working practices of the teachers in primary schools. Among the research questions were:1) What specific dilemmas face actors in teaching concerning professional integrity in Uganda? 2) What kind of reforms could be developed in partnership with the teachers in order for them to play an active role in improving the image of teaching in Uganda? This article is based on the second research question and presents a school-based strategy that would improve communication and participation in school affairs. It draws mainly from group discussions (Krueger, 1997), feedback meetings explained in Creswell, (2012) and an innovative method that was introduced by a group of 32 Nakasero Primary school teachers who were purposively selected.

\subsection{The Action Research process}

Phase one: This phase involved collecting data from a wide range of participants from both rural and urban schools. Majority of the participants were purposively selected from 5 schools. These included the learners, teachers, retired teachers, tutors, teacher trainees, and other key stakeholders to ensure maximum variation and neutrality of information (Krueger 1998). A total of 214 structured open questionnaires were administered to randomly selected teachers, and learners. Twenty-seven interviews with key stakeholders were conducted in order to get their experiences and construct a common understanding of the problem (Creswell, 2012). This was crowned by a half day stakeholder workshop to dialogue on the issues identified.

Phase two: In this phase, research was narrowed to one school - Nakasero Primary. Through three group discussions, participants highlighted improved communication, lack of transparent leadership and a sense of ownership of the organisation as being critical areas for improvement.

Phase Three: A research team of 32 teachers was organised to deliberate on what activities would bring them together to work on the issues they had identified in phase one. This article is concerned with this phase on how opportunities were created for the participants to speak to and appreciate each other as communicative equals in an effort of empowerment and emancipation. The teachers started a forum in which they openly discussed pertinent issues that affected them.

\section{Findings and Discussion}

This section presents the findings of the outcomes of the action research process by first highlighting how a forum for engagement was created, and enabled the teachers to advocate for change. I then take a step further to show how the idea of PIE was coined in the process of continued collaboration and co-learning.

\section{Teachers' advocacy for change and empowerment}

Guided by the theory of active participation in problem solving (Zeichner 2003; Boog 2007; Kemmis, 2007; Wicks and Reason 2009), our interventions were based on the notions of idealised consensus and dialogue. The concern was to work with teachers as subjects who could build knowledge about professional integrity through critical reflection on their activities within a school context. Subsequently, we settled for less ambitious innovations that would neither require additional resources nor interfere with the school routines.

The first step was to form a leadership structure that could organise the research activities. It was by general consensus that an administrator became the overall coordinator. This was essential because the teachers needed the endorsement of the school administration for reinforcing support and increasing the quality of participation (Bodorkos and Pataki 2009). The chairperson was unanimously nominated by the teachers, while the secretary volunteered. These two collaborated to organise meetings and document the proceedings. In addition, four committees were formed to spearhead the activity implementation process. 
These included: 1)- capacity building, 2) mobilising children, 3) mobilising parents and 4) producing the newsletter.

The teachers agreed on a set of guiding principles including; commitment, voluntary participation and non-interference with the school programmes. This was to demonstrate to the school authorities that the teachers were not working against the school administration. Teachers proceeded to draw up short-term plans concerning when and how each group was to meet, and when to combine in the larger group to share information generated from the smaller groups. The committee leaders mobilised other members and facilitated various discussions within the small groups before presenting key findings to the larger group. Participants also resolved to dedicate one corner in the staffroom as a 'research corner' to circulate information about the research activities in order to improve communication at the school level.

Flexibility is a critical characteristic of PAR (Kemmis (2007). For instance, meetings were usually conducted in the evenings after meeting the day job demands. The chairperson created an atmosphere that encouraged active participation for every participant and as an insider, he seemed to have a better understanding of the group dynamics and institutional politics which is essential in PAR. Subsequently, participants found their own identities harmonised with those of others as they developed a feeling of connection and ownership of the research (Wabule 2017).

The enthusiastic team conducted several peer-learning sessions for a couple of months, in which we discussed a range of problems on the research subject which they deemed impactful on professionalism at the micro, meso and macro levels. Not only did participants discuss how lack of autonomy impacted the work environment, they were also able to root their discussions in specific examples from their own experiences. Discussing personal feelings and the open moments of reflection, improved trust. Similar to what is pointed out by Zeichner (2003); expressing feelings about things that teachers considered to be hurtful gave relief from long accumulated anger as demonstrated by teacher Terzas and teacher Richard in the excerpts one and two, below:

So, some of us had to let out what we had in mind so that it can reach where we wanted it to go... the platform we got, the discussions we had were able to point out a few things that probably we were taking for granted... which were affecting the way we relate and work. (Teacher Terzas, 30 November 2015)

Such a declaration by teacher Terzas indicated how the teachers developed a stronger professional community and collaborative working culture through open discussions.

The leadership that was created enhanced the staff's commitment to participatory decision-making, as Hyland (2009) states in that the teachers collaboratively set their own agendas, voluntarily took up responsibilities in the research, became more active participants in school affairs and become mentors of one another.

In order to obtain more transformative power and influence on the research process as also pointed out by Boog (2007), it was at the discretion of the chairperson together with the secretary and team leaders to determine the agendas and make decisions on the most appropriate days, venues and times for holding meetings. I refrained from chairing meetings because I had to keep to the research ethics of not exerting much influence on participants, and also in order to keep the discussions objective. Whitehead and McNiff (2009) term this as 'moral commitment in action research', in the sense that the researchers only facilitate a process that enables people to make decisions that are right for them. This process of gaining knowledge through a process of mutual understanding is what Boog $(2007$, p. 72) refers to as "ability for self-determination." This helped participants to open up, as expressed by teacher Herbert below: 
We were encouraged to talk, talk and speak and let your voice be heard. So, we said, there is a forum now were we put our differences aside and we come together and share now, and share experiences and talk about them... (Herbert, 30 November 2015).

The chairperson continuously reminded the research team to commit to the tasks they had voluntarily pledged to fulfil so as to ensure maximum participation. These among others included activities such as, regular attendance and full participation at meetings; contribution of articles for the newsletters, and mobilisation of other stakeholders. Engaging the teachers through democratic processes, as also stressed by Whitehead and McNiff (2009), triggered thoughts from various perspectives about troubling situations and helped to contain the tensions, timidity and fear they had formerly harboured. This we could tell by the sentiments expressed, and by how teachers reacted to each other. The heated exchanges and criticisms sometimes caused anger as some participants felt that certain words were indirectly targeting them. Nonetheless, the differences created a deeper learning experience within this group of teachers such that they felt at ease. Subsequently, it enabled them to examine their own actions, and raised their confidence and esteem as 'researchers'. Participants became more reflective as they shared experiences that challenged the commonly held norms, values, beliefs and assumptions, as shared by Dan:

[W] e were able to know through our discussions that maybe we are also sometimes in the wrong, because it takes humility for one to realise their problem. Because what is easy is that we always accuse the other person, but when we say, 'wait a minute, how about me?'... we realised individual differences and how they affect each other and how we can relate... The platform we got, the discussions we had were able to point out a few things that probably we were taking for granted, which were affecting the way we relate and work. (Dan, 30 November, 2015)

A willingness to share and conceive one's own condition helped the teachers to learn from one another. Besides, reflecting on past experiences helped those who in the beginning had shown signs of negative sentiments, to now take a positive outlook. For instance, the excerpt from Dan above portrays a changed perception of dealing with unresolved problems as a form of experience rather than a source of frustration. Moreover, opening communicative space was a step in breaking the barriers of isolation, fear, low esteem and a culture of silence that had engulfed the school system:

We feared each other, and you feared to communicate in a meeting... even if there is something hurting you, you just keep quiet about it... So, when the research started... this research...this is when people opened out what they had in their mind. They have now a listening ear. They started speaking their minds... At least they have somebody now they can tell a secret, tell what hurts them, tell what pains them, and tell what is happening on the ground... (Herbert, 30 November 2015)

First, we established that, facilitating a forum for participation and engagement as indicated by the excerpts above had enabled the teachers to collaboratively reflect on their role. For the first time, the teachers had the opportunity to come together to play an important role in a bid to transform the working processes at the school. Secondly, we also saw that the forum would create a deeper and shared understanding on how to enhance autonomy through acts of teamwork, strengthened interpersonal relations and internal capacity development. Finally, sharing actual experiences, dilemmas and challenges within the school environment were manifestations of teachers engaging within their profession and the institution. It is at this point that the concept Professional Institutional Engagement (PIE) was coined. 


\section{Enhancing the process of Professional Institutional Engagement (PIE)}

The concept of PIE was introduced with a purpose of focusing more attention on the institutional context when addressing complex situations. This concept stands for a holistic approach that can deepen understanding of teachers' professional practices as they interact with the work environment (Wabule 2017). This was developed as an afterthought during the interactive forum, an innovation that aimed to transform teaching practices (Wabule 2017). Armstrong (2009) considers an engaged employee as someone who is aware of the work context and works closely with colleagues to improve performance within the job for the benefit of the organisation and clients.

For this research, PIE means, professionals engaging with both their occupation and the institutions of work, given that each work environment has specific and unique challenges. Thus, PIE is understood as a process of developing a strong connection to one's work, having a clear understanding of the realities and differences of the work environment and adapting certain innovations that respond successfully to the situation (Wabule 2017). In the context of the teaching profession, PIE directs attention to bringing about more responsive ways of dealing with school-based problems in a collegial manner. When people talk collectively about issues that impact their practices, it always leads to some solutions. Freidson (1994) denotes stakeholder participation by the term 'peer reviews', that makes it more interactive and, unlike bureaucratic methods, it can ably employ judgements finely tuned to variable individual circumstances and problems.

The PIE strategy proved useful in our collective learning process in that the teachers openly discussed matters of ethics and different aspects of behaviour and practice with one another. Even when changing an entire system may be a complex venture, PIE facilitated a process where teachers reflected on issues and sought alternative means of handling dilemmas. Just as Banks (2009) and (Kunneman 2005) note, there is no best way of handling dilemmas, but seeking a range of solutions to problems and trying them out. The focus on PIE combined with the collaborative learning strategy in the study perfectly captured the specific nature of teacher professionalism. For instance, amicable interactions with colleagues, school leadership, parents, and pupils eventually worked to break the barriers of fear, isolation and uncertainty that teachers originally faced as shared by Tina a teacher:

It has really brought that bonding... there is that bonding that we have created to each other. Leave alone the teamwork and so on. Even when we are relating in groups, we learn about one another and that is something very positive on our side. (Tina, 30 November 2015)

PIE is premised on the basis that when teachers actively engage both within their profession and the institution in a constructive way; by critically evaluating and questioning real life dilemmas, they gradually strike a balance between their personal values, the values of the profession and the institutional values. This fits well within the African context where teachers work in resource-constrained environments (Jansen 2006; UNESCO 2009; Tao 2013; Wabule 2017). Yet, like the case of Uganda, teacher training hardly equips them with adequate skills to respond to the challenging nature of the school and the classroom (Nakabugo, Bisaso and Masembe 2010; Kasente 2010; UWEZO 2013). Professional institutional engagement as a new strategy was framed with the intention of promoting the teacher's own learning in a collaborative culture; whereby both teachers and school administrators become peers and mentors as they socialise and accumulate lived experiences within the school's setting. Similar to what Botha (2011) points out, our understanding is that educators only understand the social transformation and the value of a democratic style of leadership when they start viewing mistakes as opportunities to learn. Other scholars refer to this as 'democratic pragmatism', in the sense that there is a more collaborative style of governance (Whitty, 2006). In the process, knowledge is obtained through both 
formal and informal participatory processes, and relationships are based on free and voluntary association of different stakeholders within the school system.

The key argument of PIE rests on the assumption that professional problems can be solved within the school context, through a series of compromises by different actors voluntarily identifying concerns to be discussed. Whereas this may involve a complex mixture of varying and often conflicting interests and values, Kunneman (2005) asserts that this opens up opportunity for sharing dynamic knowledge with a variety of stakeholders. An interesting element with this concept is that it advocates for the critical analysis of the work context, collaborative learning, autonomy and taking up responsibility for professional actions at both individual and group levels. This paper further supposes that teachers mutually respect each other's views in order to foster empowerment and meaningful collaboration. As Cilliers $(1998$, p. 56) rightly observes, the framework for teacher autonomy not only necessitates a redesigning of various functions, roles and responsibilities but also by crafting interventions that enhance creativity and innovative leadership.

This observation by Cilliers confirms the assertion that a successful school is a result of interaction between different players and the integrity of the school system in general (Campbell 2003; Sahlberg 2011). In this sense, teachers are not only recipients of top-down innovations at all times, but have to be engaged stakeholders in the system. Sahlberg (2011) argues that a successful school system largely depends on how well teachers exercise their professional knowledge and judgment, both widely and freely in their schools., while Freidson (1994) indicates that the ultimate goal of change is when people envision themselves with a stake in the system as a whole. Accordingly, individuals become more effective when there is genuine communication, openness and participation in decision making. Similarly, our new framework of PIE encourages interaction, learning and innovation, as well as development of relationships and staff cooperation (Wabule 2017). The assumption is that enhancing teaching abilities through mutual cooperation of all education stakeholders in a collaborative school learning environment could enhance trustful leadership, honesty, fairness, networking, thus, opening channels for endless creative potential. Sahlberg puts it clearly:

Teachers improve by learning from other teachers. Schools improve when they learn from other schools. Isolation is the enemy of all improvement, and has to be broken down in order to develop reforms that will truly inspire teachers to improve learning for all students (Sahlberg 2011, p. 20).

Moreover, we succeeded in creating an inclusive space (Bodorkos and Pataki 2009), by incorporating other significant stakeholders such as the parents, members of the teacher's union, a tutor from a primary teacher training college and experienced researchers from the academia on the research team. These mostly served on the feedback committee that provided a forum for sharing information, exchanging views, commenting and guiding the entire research process. At meetings where all these stakeholders were present, they reciprocally and openly put each other to task to explain their weaknesses. The willingness to work together opened a way to an endless creative potential where people deliberated on different issues of interest and came up with a better understanding of the other (Kemmis 2007). Besides, connecting with different people provided opportunities for team building, social cohesion and a strong sense of shared responsibility which PIE intended to promote.

Finally, the concept of PIE aligns well with literature that depicts quality teaching and a good school as being defined through the mutual interaction between the school and all the other stakeholders (Sahlberg 2011). According to Sahlberg, teachers need time to work together during a school day and understand how their colleagues teach. This is important for reflecting on the teacher's own teaching, building a shared accountability and collective learning. In this study, PIE created a favourable professional learning community where teachers developed trust for each other as they communicated frequently about 
their teaching and learning. Similar to what Sahlberg (2011) points out, the processes of learning and relearning enhanced collegial solidarity, a sense of belonging and ownership of the institution.

\section{Conclusion}

An authoritarian system of education management in Uganda has limited teachers' enthusiasm to make meaningful contribution in schools' affairs. Findings indicated that lack of autonomy led to dissatisfaction, failed innovations, diminished self-evaluation and volatility in decision making. I have demonstrated how initiating joint interventions with the teachers at one school through PAR, enabled them to negotiate space for collective learning. Establishing a forum where school challenges could be heard safely, and changed the teacher's perceptions of dealing with challenging problems as a form of experience rather than a source of frustration. Subsequently teachers felt empowered to talk openly about issues they had kept silent about.

Through a holistic institutional engagement on new practices and reflections, there emerged a concept of Professional Institutional Engagement (PIE). This concept was premised on the virtues of dialogue and a recognition of all education stakeholders as communicative equals. In the context of the teaching profession, PIE may be useful in guiding specifically teachers who work under difficult conditions to develop a strong connection to their work, a clear understanding of the realities of the work environment and adapt innovations that respond successfully to the situation (Wabule 2017). Although the PIE framework may not in itself transform the entire school system, it suggests forums for interaction that may help transform the teaching practices by establishing a trustful relationship and creating conditions where people openly talked about their issues in a democratic way, thus becoming a fundamental starting point to enhance autonomy and amplify teachers' voices.

\section{References}

Aguti, JN and Fraser, W J 2005, The Challenges of Universal Primary Education (UPE) in Uganda through distance education programmes. African Educational Review, vol. 2, no. 1, pp. 91-108.

Armstrong, M 2009, Armstrong's Essential Human Resource Management Practice: A guide to people management. London: Kogan Page Publishers.

Banks, S 2009, From Professional Ethics to Ethics in Professional Life: Implications for learning teaching study. Ethics and Social Welfare, vol. 3, no. 1, pp. 55-63.

Boog, B 2007, Quality of action research: Reciprocal understanding of academic researchers and participating researchers. In: Ponte, P. and Smit, H.J. (eds). The quality of practitioner research: Reflections on the position of the researcher and the researched. Rotterdam: Sense Publishers. pp. 6576.

Botha, RJ 2011, The managerial role of the principle in promoting teacher professionalism in selected Eastern Cape schools. African Education Review, vol. 8, no. 3, pp. 397-415.

Bodorkos, B, Pataki, G 2009, Local communities empowered to plan? Applying PAR to establish democratic communicative spaces for sustainable rural development. Action Research, vol. 7, no. 3, pp. 313-334.

Cilliers, P 1998, Complexity and post modernism: Understanding the complex systems. London: Routledge.

Creswell, JW 2012, Education Research: Planning, Conducting and Evaluating Quantitative and Qualitative Research, 4th ed. Boston: Pearson.

Freidson, E 1994, Professionalism reborn. Theory, Prophecy and Policy. Cambridge: Policy Press

Fullan, M 2010, Motion leadership. The skinny on becoming hanger savvy. Thousand Oaks. CA: Corwin Press.

Hyland, NE 2009, Opening and closing communicative space with teachers investigating race and racism in their own practice. Action Research, vol. 7, pp. 335-354.

Jansen, JD (2006). Autonomy and Accountability in the Regulation of the Teaching Profession: A South African Case Study. Research Papers in Education, vol. 19, no. 1, pp. 51-66. 
Kasente, D 2010, Enhancing the quality of primary education in Uganda. A case for improved literacy and improving the quality of teaching. Kampala: Fountain Publishers.

Kemmis, S 2007, Participatory Action Research and the Public Sphere. In: Ponte, P. and Smit, B.H.J. (eds). The quality of practitioner research: Reflections on the position of the researcher and the researched. Rotterdam: Sense Publishers' pp. 9-27.

Kunneman, H 2005, Social work as laboratory for normative professionalism. Social Work and Society, vol. 3, no. 2, pp. 191-200.

Krueger, R A 1998, Analysing and Reporting Focus Group Results. Southern Oaks, London: Sage Publications.

Lugumba, SME, Ssekamwa, J C (1973). A history of education in East Africa (1900-1973). Kampala Bookshop, Pub. Dept.

Moses, I 2007, Institutional autonomy revisited: Autonomy justified and accounted. Higher Educational Policy, vol. 20, no. 3, pp. 261-273.

Munakukaama, NJ 1997, Secularization of Post-Independence Education in Uganda, and its Significance for Moral Education in Public Primary and Secondary Schools 1963-1985. Makerere University, unpublished $\mathrm{PhD}$ thesis.

Nakabugo, M G, Bisaso, R, Masembe, CS 2010, The Continuum of Teacher Professional Development: Towards a coherent approach to the development of secondary school teachers in Uganda, aadcice. Hiroshima-u.ac.jp/e/publications/sosh04-2-14.pdf.

Nengwekhulu, RH 2008, Reflections on improving teacher performance. Africa Education Review, vol. 5, no. 2, pp. 338-350.

Pollard, A, Black-Hawkins, K, Cliff-Hodges, G, Dudley, P, James, M (2014). Reflective teaching in Schools: Evidence- Informed Professional Practice. London: Bloomsbury Publishing.

Sahlberg, P 2011, Finnish Lessons: What can the world learn from the educational change in Finland? New York and London: Teachers College Press.

Tao, S 2013, Why are teachers absent? Utilising the capability approach and critical realism to explain teacher performance in Tanzania. International Journal of Education Development, vol. 33, no. 1, pp. $2-14$.

UNESCO 2014, Teacher issues in Uganda. UNESCO. Org/images/00229/22977e.pdf. (accessed on August 6th 2020).

UWEZO Uganda 2013, Are our children learning? Literacy and Numeracy across East Africa. http://www.uwezo.net/wp-content/uploads/2012/08/2013-Annual- Report-Final-Web-version.pdf. (accessed on 6th August 2020).

Van Strien, PJ 2007, Towards a methodology of psychological practice: the regulative cycle. Theory and Psychology, vol. 7, no. 5, pp. 683-700.

Van Veen, K 2008, Analysing teacher's working conditions from the perspective of teachers as professionals: The case of Dutch high school teachers. In: Ax, J. and Ponte, P. (eds.). Critiquing Praxis: Conceptual and empirical trends in the teaching profession. Rotterdam: Sense publishers, pp. 91-112.

Wabule, A 2020, Resilience and Care: How teachers deal with situations of adversity in the teaching and learning environment. The independent Journal of Teaching and Learning. vol. 15, no. 1, pp. 76-90.

Wabule, A 2017, Professional Integrity of Teachers in Uganda: Practical Action Strategies Groningen: Globalisation Studies Groningen.

Whitehead, J, McNiff, JC 2009, Doing and writing action research. London, Sage Publications.

Whitty, G. (2006). Teacher professionalism in the new era. Paper presented at the first General Teaching Council for Northern Ireland Annual Lecture, Belfast, March 2006.

Wicks, PG, Reason, P 2009, Initiating action research: Challenges and paradoxes of opening communicative space. Action Research, vol. 7, no. 3, pp. 243-262.

Zeichner, K M 2003, Teacher research as professional development for P-12 educators in the USA. Educational Action Research, vol. 11, no. 2, pp. 301-326. 